\section{Microbiological quality and presence of foodborne pathogens in raw milk cheeses and raw meat products market- ed at farm level in Switzerland}

\author{
Nathalie Spoerry Serrano, \\ Claudio Zweifel, Sabrina Corti, \\ Roger Stephan
}

Institute for Food Safety and Hygiene, Vetsuisse Faculty University of Zurich, Switzerland

\section{Abstract}

This study investigated the microbiological quality and presence of bacterial foodborne pathogens in 51 raw milk cheeses (mainly semihard and hard cheese) and 53 raw meat products (cured meat products and sausages) marketed at farm level. With regard to Enterobacteriaceae, Escherichia (E.) coli, and coagulase-positive staphylococci (CPS), the examined products were generally of a good microbiological quality. Enterobacteriaceae were found in seven cheeses $\left(1.0 \times 10^{2}\right.$ $\left.8.8 \times 10^{4} \mathrm{CFU} / \mathrm{g}\right)$ and one sausage $\left(2.0 \times 10^{2} \mathrm{CFU} / \mathrm{g}\right)$. Three of these cheeses were also positive for E. coli. CPS results were comparable for cheeses $\left(5.9 \% ; 1.0-6.0 \times 10^{2} \mathrm{CFU} / \mathrm{g}\right)$ and meat products $\left(3.8 \% ; 1.0-2.0 \times 10^{2}\right.$ $\mathrm{CFU} / \mathrm{g}$ ). On the other hand, such raw products may harbor potential health hazards as Listeria (L.) monocytogenes, Shiga toxin-producing E. coli (STEC), and staphylococcal enterotoxin (SE)producing Staphylococcus (S.) aureus. L. monocytogenes were found in one sausage and the isolate belonged to the serotype $1 / 2 \mathrm{c}$. The two STEC isolates harbored stx 1a (cheese) or stx $2 \mathrm{e}$ (sausage), but both lacked eae and did not belong to the top five-serogroups. Of the five $S$. aureus isolates, the three cheese isolates belonged to the clonal complex (CC) 8, CC22, and CC705, the two sausage isolates belonged to $\mathrm{CC} 7$, and all isolates harbored genes for SEs. Thus, to avoid contaminations and to prevent foodborne pathogens from entering the food chain, strict compliance with good hygiene practices during milk and cheese produc- tion or meat production is of central importance.

\section{Introduction}

In recent years, eating and consumption habits have radically changed under the influence of lifestyle changes and new technologies (Kearney, 2010; Regmi, 2001). Alongside the emergence of convenience and fast food products, natural and unheated foods of animal origin have gained popularity with consumers. In particular products marketed at farm level are thereby considered as healthy and associated with well-treated animals. Hence, many farmers have discovered direct selling of foods as niche market and they offer various products through different channels, e.g. farm shops, farmers markets, or home delivery.

Among foods sold at farm level, cheeses and meat products are of popularity with consumers. Sold cheeses comprise a wide variety of products (e.g. fresh, soft, semihard, or hard cheese) that can be produced from milk of different animal species. Thereby, many cheese varieties throughout Europe are typically made from unpasteurized milk with the natural enzymes and microflora responsible for enhancing desirable flavor characteristics. Sold meat products often comprise cured products as ham or bacon and (fermented) raw sausages as salami, foods usually intended to be eaten raw. However, comprehensive data on the microbiological quality of such raw products marketed at farm level are currently limited. The aim of this study was therefore to generate initial baseline data on general hygienic parameters and selected bacterial foodborne pathogens in raw milk cheeses and raw meat products sold directly from farms.

\section{Materials and Methods}

\section{Analyzed products}

In this study, 51 raw milk cheeses and 53 raw meat products marketed at farm level were analyzed. The 51 raw milk cheeses were grouped in four cat-
Correspondence: Roger Stephan, Institute for Food Safety and Hygiene, Vetsuisse Faculty University of Zurich Winterthurerstrasse 272, 8057 Zurich, Switzerland.

Tel.: +41.44.635.8651 - Fax: +41.44.6358908

E-mail: roger.stephan@uzh.ch.

Key words: Raw milk and meat products; Farm level; Listeria monocytogenes; Shiga toxin-producing Escherichia coli; Staphylococcus aureus.

Acknowledgments: the authors thank Regina Imfeld, Nicole Cernela, and Marina Morach for their technical assistance.

Contributions: the authors contributed equally.

Conflict of interest: the authors declare no potential conflict of interest.

Funding: none.

Received for publication: 10 February 2018 Revision received: 5 April 2018.

Accepted for publication: 10 April 2018

This work is licensed under a Creative Commons Attribution-NonCommercial 4.0 International License (CC BY-NC 4.0).

CCopyright N.S. Serrano et al., 2018

Licensee PAGEPress, Italy

Italian Journal of Food Safety 2018; 7:7337

doi:10.4081/ijfs.2018.7337

egories: semihard/hard cheese $(n=45)$, fresh cheese $(n=4)$, soft cheese $(n=1)$, and sour cheese $(n=1)$. The semihard/hard cheeses were produced from cow milk $(n=40)$, goat milk $(n=4)$, and sheep milk $(n=1)$. Thirty of them were produced on mountain pastures. The fresh cheeses were produced from goat milk $(\mathrm{n}=3)$ and water buffalo milk $(n=1)$. The soft and sour cheeses were both produced from cow milk. The 53 raw meat products intended to be eaten raw were grouped in two categories: cured meat products $(n=14$, e.g. ham or bacon) and raw sausages $(n=39$, e.g. salami). The meat composition was quite variable. Cured meat products were produced from beef $(n=7)$, pork $(n=5)$, mutton $(n=1)$, and water buffalo meat $(n=1)$. Raw sausages were produced from beef and pork $(n=18)$, meat of unknown origin $(n=7)$, beef $(n=4)$, pork $(n=2)$, mutton $(n=2)$, water buffalo meat $(n=2)$, goat meat $(n=2)$, pork and mutton $(\mathrm{n}=1)$, and beef and poultry $(\mathrm{n}=1)$. 


\section{Sample collection and preparation}

Samples (raw milk cheeses and raw meat products) were bought at farm level and they originated from 63 farms located in the central, northern, and eastern part of Switzerland. Samples were transported chilled to the laboratory. Before processing, the rind of semihard/hard cheeses was cut away, raw sausages were peeled (if possible), and the bacon rind was removed.

Total viable counts,

Enterobacteriaceae, Escherichia coli, coagulase-positive staphylococci, and Listeria monocytogenes

A subset of each sample (10 g) was homogenized at a $1: 10$ ratio in $0.85 \%$ $\mathrm{NaCl}$ and quantitatively analyzed by spreading $0.1 \mathrm{~mL}$. The following agars and conditions were used: plate count agar (Oxoid, Pratteln, Switzerland; 72 $\mathrm{h}, 30^{\circ} \mathrm{C}$ ) for total viable counts (TVC), violet red bile glucose agar (Becton Dickinson, Allschwil, Switzerland; 48 $\mathrm{h}, 30^{\circ} \mathrm{C}$, anaerobic conditions) for Enterobacteriaceae, Rapid Escherichia (E.) coli 2 agar (Bio-Rad, Reinach, Switzerland; $24 \mathrm{~h}, 37^{\circ} \mathrm{C}$ ) for $E$. coli, rabbit plasma fibrinogen agar (Bio$\mathrm{Rad} ; 48 \mathrm{~h}, 37^{\circ} \mathrm{C}$ ) for coagulase-positive staphylococci (CPS), and Rapid L.mono agar (Bio-Rad; $48 \mathrm{~h}, 37^{\circ} \mathrm{C}$ ) for Listeria (L.) monocytogenes. For the quantitative analyses mentioned above, the detection limit was $100 \mathrm{CFU} / \mathrm{g}$ $\left(1.0 \times 10^{2} \mathrm{CFU} / \mathrm{g}\right)$.

\section{Salmonella spp.}

For detection of Salmonella spp., 25 $\mathrm{g}$ of each sample were enriched first at a 1:10 ratio in buffered peptone water (Oxoid; $24 \mathrm{~h}, 37^{\circ} \mathrm{C}$ ) and subsequently in $10 \mathrm{ml}$ of Rappaport-Vassiliadis broth (Oxoid; $24 \mathrm{~h}, 41.5^{\circ} \mathrm{C}$ ). The enriched samples were subcultured on xyloselysine-desoxycholate agar (Bio-Rad; $24 \mathrm{~h}, 37^{\circ} \mathrm{C}$ ) and mannitol lysine crystal violet brilliant green agar (Oxoid; $24 \mathrm{~h}$, $37^{\circ} \mathrm{C}$ ).

\section{Shiga toxin-producing Escherichia coli}

For detection of Shiga toxin genes (stx), $10 \mathrm{~g}$ of each sample were enriched first at a 1:10 ratio in modified tryptic soy broth (Oxoid) with $1 \mathrm{mg} / \mathrm{L}$ acriflavin $\left(24 \mathrm{~h}, 37^{\circ} \mathrm{C}\right)$ and subsequently subcultured $\left(24 \mathrm{~h}, 37^{\circ} \mathrm{C}\right)$ on sheep blood agar (Difco Columbia blood agar base EH, Becton Dickinson; 5\% sheep blood SB055, Oxoid). After washing off the colonies $(0.85 \% \mathrm{NaCl})$, samples were screened by the Assurance GDS assay for Shiga toxin genes (Bio Control Systems, Bellevue, WA, USA).

For isolation of Shiga toxin-producing Escherichia coli (STEC), stx-positive enrichment cultures were streaked in triplicate on Rapid E. coli 2 agar (Bio-Rad; $24 \mathrm{~h}, 37^{\circ} \mathrm{C}$ ). Three typical $E$. coli colonies were picked from each plate, subcultured (plate count agar; 24 $\mathrm{h}, 37^{\circ} \mathrm{C}$ ) and tested for Shiga toxin genes (EU Reference Laboratory, 2013) by real-time PCR (LightCycler, Roche Diagtnostics, Rotkreuz, Switzerland) using the QuantiFast Multiplex PCR Kit (Qiagen, Hombrechtikon, Switzerland). Obtained STEC isolates were examined by PCR for $s t x 1$, stx 2 , and subtypes, eae (intimin) and the top-five serogroups O26, O103, O111, O145, and $\mathrm{O} 157$ (EU Reference Laboratory, 2013, 2014).

\section{Methicillin-resistant Staphylococcus aureus}

For detection of methicillin-resistant Staphylococcus aureus (MRSA), $10 \mathrm{~g}$ of each sample were enriched first at a 1:10 ratio in Mueller-Hinton broth with $6.5 \% \mathrm{NaCl}\left(24 \mathrm{~h}, 37^{\circ} \mathrm{C}\right)$ and subsequently in $5 \mathrm{ml}$ tryptone soy broth (TSB; Oxoid) with $75 \mathrm{mg} / \mathrm{L}$ aztreonam and $5 \mathrm{mg} / \mathrm{L}$ cefoxitin $\left(24 \mathrm{~h}, 37^{\circ} \mathrm{C}\right)$. The enriched samples were subcultured on chromogenic Brilliance MRSA 2 agar (Oxoid; 24 h, $37^{\circ} \mathrm{C}$ ).

\section{Staphylococcus aureus}

For confirmation of CPS as Staphylococcus (S.) aureus and for further strain characterization, the StaphType DNA microarray assay was used (Alere Technologies, Jena, Germany). This assay covers a variety of target sequences, including $S$. aureus species markers, genes encoding staphylococcal enterotoxins (SEs) and enterotoxin-like proteins, or resistanceassociated genes. Resulting DNA microarray profiles were used to assign the $S$. aureus isolates to clonal complexes (Ebner et al., 2013).

\section{pH value and water activity (aw)}

To determine $\mathrm{pH}$ and $\mathrm{a}_{\mathrm{w}}$ values, a SevenCompact $\mathrm{pH}$ meter (Mettler Toledo, Greifensee, Switzerland) and an AQUALAB water activity meter 3TE (METER Food, Munich, Germany) were used.

\section{Results and Discussion}

\section{Hygiene parameters}

The majority (56.9\%) of total viable counts (TVC) from the 51 raw milk cheeses were in the range from $10^{7}$ to $10^{8} \mathrm{CFU} / \mathrm{g}$, followed by counts between $10^{6}$ and $10^{7} \mathrm{CFU} / \mathrm{g}$. The distribution of counts for the different cheese categories is shown in Table 1. For products made from raw milk and often with addition of starter cultures, observed TVC levels were not unusual. For the 53 raw meat products, TVC were mainly $(67.9 \%)$ in the range from $10^{7}$ to $10^{9} \mathrm{CFU} / \mathrm{g}$ (Table 1 ). In particu-

Table 1. Total viable counts (TVC) from raw milk cheeses and raw meat products marketed at farm level.

\begin{tabular}{lcccccc} 
Products & $\begin{array}{c}\text { No of } \\
\text { samples }\end{array}$ & \multicolumn{4}{c}{ No. (\%) of TVC at different ranges (CFU/g) } \\
Raw milk cheeses & 51 & $1(2.0)$ & $4(7.8)$ & $9(17.6)$ & $29(56.9)$ & $8(15.7)$ \\
Semihard/hard cheese & 45 & 1 & 4 & 8 & 28 & 4 \\
\hline Soft cheese & 1 & 0 & 0 & 0 & 1 & 0 \\
Fresh cheese & 4 & 0 & 0 & 1 & 0 & 3 \\
\hline Sour cheese & 1 & 0 & 0 & 0 & 0 & 1 \\
Raw meat products & 53 & $4(7.5)$ & $6(11.3)$ & $7(13.2)$ & $23(43.4)$ & $13(24.5)$ \\
\hline Cured meat products & 14 & 3 & 3 & 5 & 3 & 0 \\
Raw sausages & 39 & 1 & 3 & 2 & 20 & 13 \\
\hline
\end{tabular}


lar but as to be expected for fermented products, more than $80 \%$ of the raw sausages showed TVC between $10^{7}$ and $10^{9} \mathrm{CFU} / \mathrm{g}$.

Enterobacteriaceae were detected in $13.7 \%$ and E. coli in $5.9 \%$ of the 51 raw milk cheeses sold from farms (Table 2). Counts of the positive cheeses ranged from $1.0 \times 10^{2}$ to $8.8 \times 10^{4} \mathrm{CFU} / \mathrm{g}$ for Enterobacteriaceae and from $4.0 \times 10^{2}$ to $8.8 \times 10^{4} \mathrm{CFU} / \mathrm{g}$ for E. coli (Table 3). When Enterobacteriaceae and E. coli were present simultaneously, Enterobacteriaceae were mainly $E$. coli. With regard to cheese category and milk origin (Table 3), four $(8.9 \%$; $\mathrm{K} 22, \mathrm{~K} 23, \mathrm{~K} 48, \mathrm{~K} 49$ ) of the 45 semihard/hard cheeses were positive for Enterobacteriaceae. They were produced from cow and goat milk and three of them originated from mountain pasture. On the other hand, three (K15, $\mathrm{K} 25, \mathrm{~K} 34)$ of the four fresh cheeses were positive for Enterobacteriaceae. They were produced from goat and buffalo milk. A goat milk fresh cheese (K15) thereby showed the highest Enterobacteriaceae and E. coli counts (almost $10^{5} \mathrm{CFU} / \mathrm{g}$ ) found in the present study. Hence, although numbers are not representative, raw milk cheeses produced on mountain pasture (special hygienic challenges), raw milk cheeses produced from goat and water buffalo milk, and fresh cheeses seem more likely to be contaminated with Enterobacteriaceae (and E. coli). Of the 53 raw meat products sold from farms, $1.9 \%$ and $0 \%$ were positive for Enterobacteriaceae and E. coli, respectively (Table 2). The positive meat product (F42) belonged to the category raw sausage, showed an
Enterobacteriaceae count of $2.0 \times 10^{2}$ $\mathrm{CFU} / \mathrm{g}$, and was produced from pork (Table 3).

Coagulase-positive staphylococci (CPS) were used as indicators for $S$. aureus. CPS were detected in $5.9 \%$ of the 53 raw milk cheeses and $3.8 \%$ of the 51 raw meat products sold from farms (Table 2). CPS counts thereby ranged from $1.0 \times 10^{2}$ to $6.0 \times 10^{2} \mathrm{CFU} / \mathrm{g}$ (Table 3). The three positive cheeses were produced from cow milk and comprised two semihard cheeses (K14,

Table 2. Enterobacteriaceae, Escherichia (E.) coli, coagulase-positive staphylococci (CPS), and Listeria monocytogenes results from raw milk cheeses and raw meat products marketed at farm level.

\begin{tabular}{lcccc}
$\begin{array}{l}\text { Products, } \\
\text { microorganisms }\end{array}$ & $\begin{array}{c}\text { No. (\%) of } \\
\text { results } \geq \\
\text { detection limit }\end{array}$ & $\begin{array}{c}\text { No. of results at different } \\
\text { ranges (CF U/g) } \\
10^{3}-10^{4}\end{array}$ & $\begin{array}{c}10^{4}-10^{5} \\
\text { Raw milk cheeses }(\mathrm{n}=51)\end{array}$ \\
Enterobacteriaceae & $7(13.7)$ & 3 & 2 & 2 \\
E. coli & $3(5.9)$ & 1 & 1 & 1 \\
CPS & $3(5.9)$ & 3 & 0 & 0 \\
L. monocytogenes & $0(0.0)$ & 0 & 0 & 0 \\
Raw meat products (n=53) & $1(1.9)$ & 1 & 0 & 0 \\
Enterobacteriaceae & $0(0.0)$ & 0 & 0 & 0 \\
E. coli & $2(3.8)$ & 2 & 0 & 0 \\
CPS & $1(1.9)$ & 1 & 0 & 0 \\
L. monocytogenes & & & & \\
\hline
\end{tabular}

Table 3. Characteristics of raw milk cheeses and raw meat products with Enterobacteriaceae, Escherichia (E.) coli, coagulase-positive staphylococci (CPS), or Listeria monocytogenes results above the detection limit $\left(1.0 \times 10^{2} \mathrm{CFU} / \mathrm{g}\right)$.

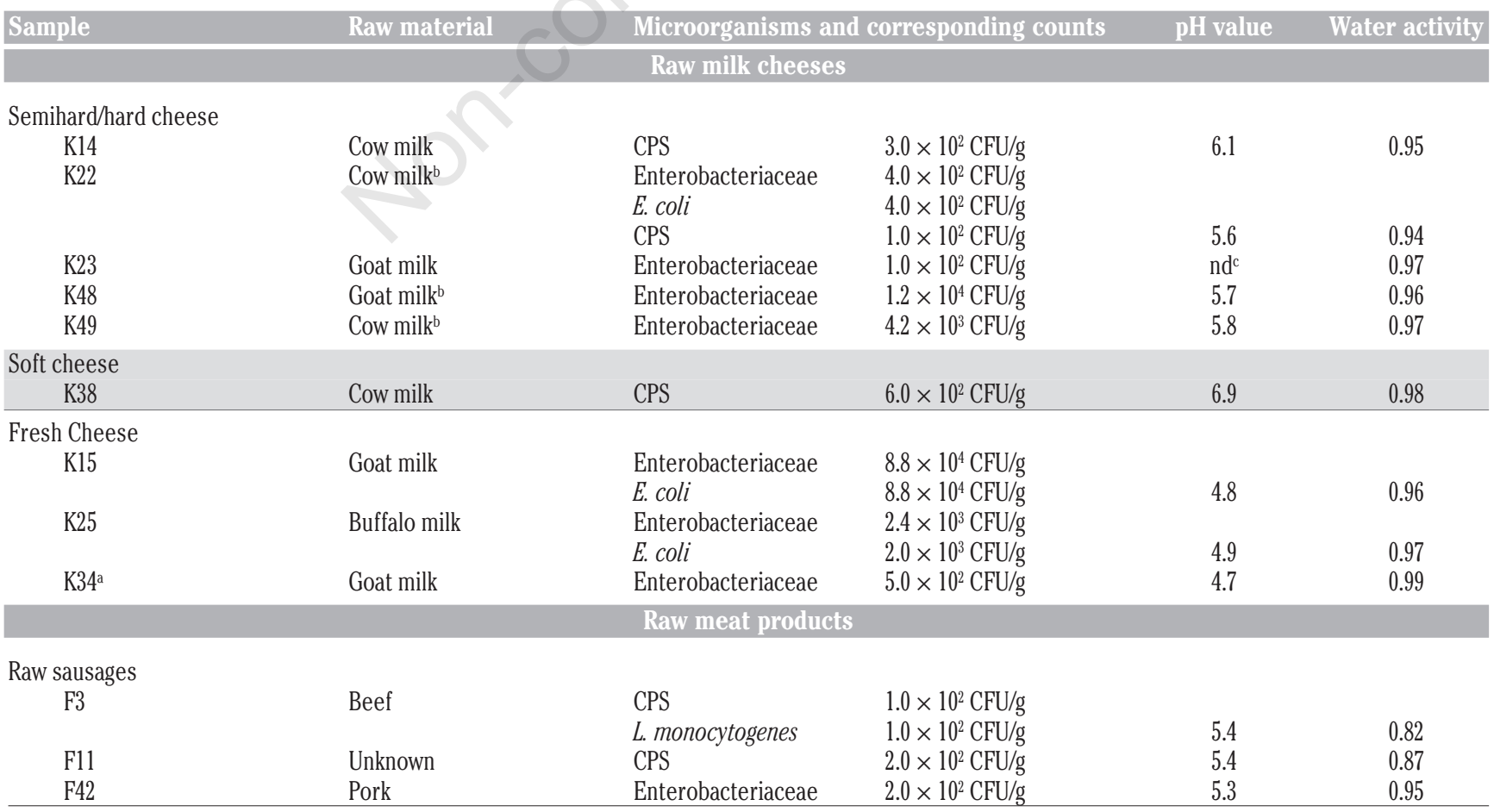

aln addition, an STEC isolate (stxla) was obtained from K34. ${ }^{\mathrm{b}}$ Cheeses produced on mountain pastures. ${ }^{\mathrm{c}}$ Not determined. 
K22) and one soft cheese (K38). The two positive meat products belonged to the category raw sausage and were produced from beef (F3) or meat of unknown origin (F11).

\section{Foodborne pathogens}

All 51 raw milk cheeses and 53 raw meat products sold from farms tested negative for Salmonella spp. (not detectable in $25 \mathrm{~g}$ ). Salmonella spp. are still a major cause of foodborne diseases, but according to the EU zoonoses report the proportion of meat products intended to be eaten raw or of cheeses not complying with the EU Salmonella criteria was low (EC, 2005; EFSA/ECDC, 2017).

As a foodborne pathogen, L. monocytogenes has the potential to cause serious and life-threatening conditions (including septicemia, meningitis, and abortion) in persons with reduced immunity (Allerberger and Wagner, 2010). Human clinical cases are thereby frequently associated with strains of serotypes 1/2a, 1/2b, and $4 \mathrm{~b}$ (Gianfranceschi et al., 2009; LopezValladares et al., 2014). In the present study, L. monocytogenes were detected in $0 \%$ of the 51 raw milk cheeses and $1.9 \%$ of the 53 raw meat products sold from farms. Our results are in agreement with a previous study examining semihard raw milk cheese during production (Zweifel et al., 2006), but it must be considered that cheese surfaces/rinds (semihard/hard cheese) were not examined and L. monocytogenes are more likely to be found in association with soft cheese. The $L$. monocytogenes-positive meat product (F3) belonged to the category raw sausage, was produced from beef, and showed a $L$. monocytogenes count of $1.0 \times 10^{2} \mathrm{CFU} / \mathrm{g}$ (Table 3). The L. monocytogenes isolate obtained from the beef sausage belonged to the serotype $1 / 2$ c. With regard to EU legislation (EC, 2005), the respective beef sausage was in compliance with the EU criterion for ready-to-eat products not supporting growth of L. monocytogenes. On the other hand, some of the products showed $\mathrm{a}_{\mathrm{w}}$ and $\mathrm{pH}$ values (see below) probably supporting the growth of L. monocytogenes (EC, 2005). Thus, samples were additionally analyzed qualitatively for L. monocytogenes (two step enrichment: Half-Fraser broth (Oxoid; $30^{\circ} \mathrm{C}, 24 \mathrm{~h}$ ), Fraser broth (Oxoid; $30^{\circ} \mathrm{C}, 24 \mathrm{~h}$ ); Rapid-L.mono agar plate (Bio-Rad; $37{ }^{\circ} \mathrm{C}, 24 \mathrm{~h}$ )). However, none of the examined products tested positive in the qualitative assay.

Shiga toxin-producing E. coli (STEC) can cause foodborne gastrointestinal illnesses in humans and conditions may be complicated by neurological and renal sequelae, including the life-threatening hemolytic uremic syndrome (Karch et al., 2005; Fruth et al., 2015). STEC are characterized by the production of Shiga toxins (Stx1, Stx2, and subtypes). STEC pathogenic for humans tend to feature Stx2 (in particular Stx2a and/or Stx2c) and other virulence traits as the adhesion factor intimin. In the present study, Shiga toxin genes were detected by the Assurance GDS assay in three $(2.9 \%)$ of the 104 raw products sold from farms. STEC isolates were obtained from a goat milk fresh cheese (K34) and a beef/pork sausage (F45). Previous studies have shown that raw milk cheeses and raw sausages can be potential sources for transmission of STEC pathogenic to humans (Currie et al., 2018; Ethelberg et al., 2009; MacDonald et al., 2004; Schimmer et al., 2008; Zweifel et al., 2010). The importance of reducing STEC contamination of raw milk or meat and of maintaining process hygiene must therefore be emphasized. The two STEC isolates found in the present study harbored stx1a (K34) or stx2e (F45), but both lacked eae (intimin) and did not belong to the top-five serogroups (O26, O103, O111, O145, O157). Isolates harboring stx2e are typically found among pigs and isolates from pigs and humans differ in their virulence profiles (Fratamico et al., 2004; Sonntag et al., 2005; Zweifel et al., 2006). Hence, STEC from the examined raw products are unlikely to cause severe human disease, but such isolates might acquire virulence factors by horizontal gene transfer.

In addition of being a commensal colonizer and being involved in various symptoms, $S$. aureus can also cause staphylococcal food poisoning (SFP) in humans (Johler and Stephan 2010; Le Loir et al., 2003). SFP results from ingestion of heat-stable staphylococcal enterotoxins (SEs), in particular SEASEE, and SFP is characterized by nausea, emesis, abdominal cramps, and diarrhea. Of the five $S$. aureus isolates characterized by DNA microarray profiling, the three cheese isolates (K14, $\mathrm{K} 22, \mathrm{~K} 38)$ belonged to the clonal complex (CC) 8, CC22, and CC705 and harbored genes for various newly described SEs and enteroxin-like proteins (e.g. the enterotoxin gene cluster, $e g c)$. The two sausage isolates (F3, F11) belonged to the $\mathrm{CC} 7$ and were positive for the gene encoding SEA. Recently, an SFP outbreak due to soft cheese contaminated with $\mathrm{CC} 8 \mathrm{~S}$. aureus producing SEA and SED has occurred at a Swiss boarding school (Johler et al., 2015b). Moreover, there is evidence for cheese-associated SFP outbreaks caused by egc-encoded enterotoxins (Johler et al., 2015a). Of the various resistance-associated genes tested, a cheese $S$. aureus isolate (K14) harbored blaZ/R/I (B-lactam resistance), $s d r M$ (putative transport protein), and fos $B$ (putative fosfomycinbleomycin resistance gene). The other S. aureus isolates were positive only for $\operatorname{sdrM}(\mathrm{K} 38, \mathrm{~F} 3, \mathrm{~F} 11)$ or lacked all tested genes (K22). With regard to antibiotic resistance, MRSA are a problem involving not only the health care system but also the general community, the environment, animals, and food products (Otter and French, 2010; Vanderhaeghen et al., 2010). In our study, applying selective methods, no MRSA were detected among the 104 examined raw products.

\section{pH value and water activity (aw)}

Analyses of $\mathrm{pH}$ and $\mathrm{a}_{\mathrm{w}}$ values were performed to assess potential bacterial growth. The $\mathrm{pH}$-range for growth of many bacteria is between 4.5 and 9.0, whereas the minimal $a_{w}$ value is 0.95 for most gram-negative bacteria (e.g. Enterobacteriaceae) and 0.86 for $S$. aureus (Krämer and Prange, 2011). However, for products having a natural bacterial flora or being produced using starter cultures, the competitive effect is crucial when assessing potential 


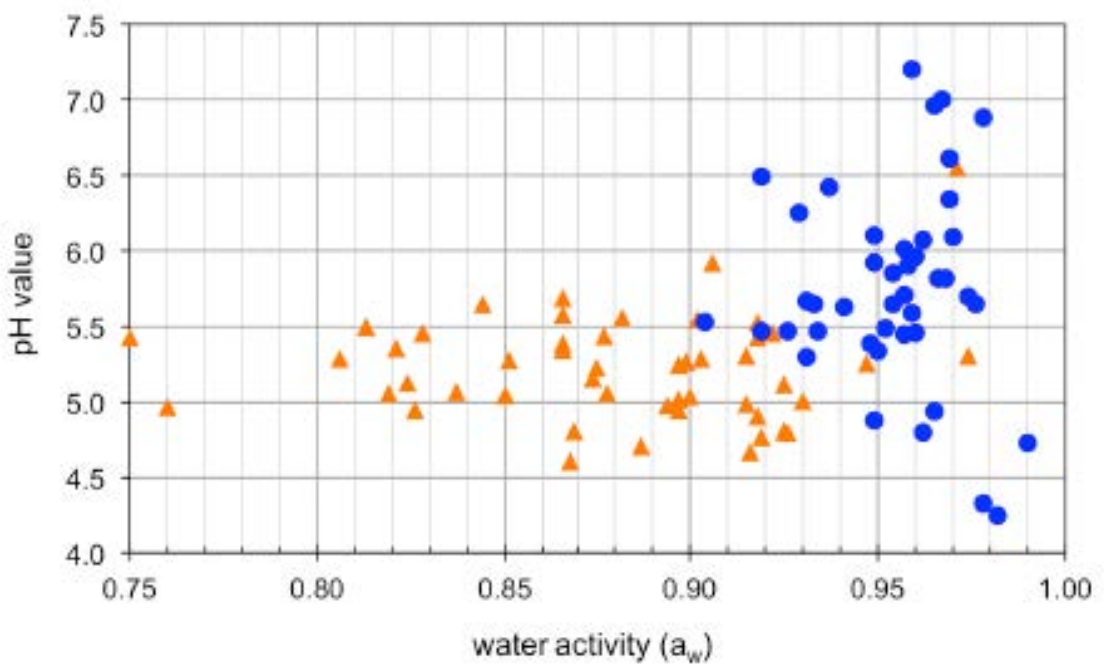

Figure 1. $\mathrm{pH}$ values and water activity $\left(\mathrm{a}_{\mathrm{w}}\right)$ of raw milk cheeses $(O)$ and raw meat products $(\triangle)$ marketed at farm level (eight cheeses and four meat products excluded due to incomplete data).

growth. The $\mathrm{pH}$ and $\mathrm{a}_{\mathrm{w}}$ values of the examined raw milk cheeses and raw meat products are shown in Figure 1. For the raw products positive for Enterobacteriaceae, E. coli, CPS, or $L$. monocytogenes, $\mathrm{pH}$ values ranged from 4.7 to 6.9 for cheeses and 5.3 to 5.4 for sausages, whereas $a_{w}$ values were mainly $\geq 0.95$ for cheeses and between 0.82 and 0.95 for sausages (Table 3 ).

\section{Conclusions}

This study generated initial baseline data on the microbiological quality and the presence of bacterial foodborne pathogens in raw milk cheeses (semihard/hard cheese, fresh cheese, soft cheese, sour cheese) and raw meat products (cured meat products, raw sausages) marketed at farm level in Switzerland. With regard to the detection and counts of Enterobacteriaceae, $E$. coli, and CPS, the examined products were generally of a good microbiological quality. However, raw milk cheeses produced on mountain pasture, raw milk cheeses produced from goat (and water buffalo) milk, and fresh cheeses seem more likely to be contaminated with Enterobacteriaceae (and $E$. coli). On the other hand, it was shown that such raw products may harbor potential health hazards as $L$. monocy- togenes, STEC, and SE-producing $S$. aureus. However, the L. monocytogenes isolate (beef sausage) belonged to a serotype not typically associated with human listeriosis, due to their virulence factors the STEC isolates (goat milk fresh cheese; beef/pork sausage) are unlikely to cause severe human disease, and growth of SE-producing $S$. aureus is not to be expected in products with competitive natural bacterial floras or starter cultures. Nevertheless, to avoid contaminations and to prevent foodborne pathogens from entering the food chain, strict compliance with good hygiene practices during any step of milk and cheese production or meat production is of central importance.

\section{References}

Allerberger F, Wagner M, 2010. Listeriosis: a resurgent foodborne infection. Clin Microbiol Infect 16:16-23.

Currie A, Galanis E, Chacon PA, Murray R, Wilcott L, Kirkby P, Honish L, Franklin K, Farber J, Parker R, Shyng S, Sharma D, Tschetter L, Hoang L, Chui L, Pacagnella A, Wong J, Pritchard J, Kerr A, Taylor M, Mah V, Flint J, 2018. Outbreak of Escherichia coli O157:H7 infections linked to aged raw milk Gouda cheese, Canada,
2013. J Food Prot 81:325-31.

Ebner R, Johler S, Sihto HM, Stephan R, Zweifel C, 2013. Microarraybased characterization of Staphylococcus aureus isolates obtained from chicken carcasses. J Food Prot 76:1471-4.

EC, 2005. Regulation of the European Commission (EC) No. 2073/2005 of 15 November 2005 on microbiological criteria for foodstuffs. In: Official Journal, L338/1-26.

EFSA/ECDC, 2017. The European Union summary report on trends and sources of zoonoses, zoonotic agents and food-borne outbreaks in 2017. EFSA J 15:5077.

Ethelberg S, Smith B, Torpdahl M, Lisby M, Boel J, Jensen T, Nielsen EM, Mølbak K, 2009. Outbreak of non-O157 Shiga toxin-producing Escherichia coli infection from consumption of beef sausage. Clin Infect Dis 48:e78-81.

EU Reference Laboratory for E. coli, 2013. Identification and characterization of Verocytotoxin-producing Escherichia coli (VTEC) by Real Time PCR amplification of the main virulence genes and the genes associated with the serogroups mainly associated with severe human infections. EU-RL VTEC_Method_02_Rev 0 . Available at: http://www.iss.it/vtec/index.php?la $\mathrm{ng}=2 \&$ tipo $=3 . \quad$ Accessed 10 February 2018.

EU Reference Laboratory for E. coli, 2014. Identification of the VTEC serogroups mainly associated with human infections by conventional PCR amplification of O-associated genes. EU-RL VTEC_Method_03_Rev 01 . Available at: http://www.iss.it/vtec/index.php?la ng $=2 \&$ tipo $=3$. Accessed 10 February 2018.

Fratamico PM, Bagi LK, Bush EJ, Solow BT, 2004. Prevalence and characterization of Shiga toxin-producing Escherichia coli in swine feces recovered in the National Animal Health Monitoring System's Swine 2000 study. Appl Environ Microbiol 70:7173-8.

Fruth A, Prager R, Tietze E, Rabsch W, 
Flieger A, 2015. Molecular epidemiological view on Shiga toxinproducing Escherichia coli causing human disease in Germany: diversity, prevalence, and outbreaks. Int J Med Microbiol 305:697-704.

Gianfranceschi MV, D'Ottavio MC, Gattuso A, Bella A, Aureli P, 2009. Distribution of serotypes and pulsotypes of Listeria monocytogenes from human, food and environmental isolates (Italy 2002-2005). Food Microbiol 26:520-6.

Johler S, Giannini P, Jermini M, Hummerjohann J, Baumgartner A, Stephan R, 2015a. Further evidence for staphylococcal food poisoning outbreaks caused by egc-encoded enterotoxins. Toxins 7:997-1004.

Johler S, Stephan R, 2010. Staphylococcal food poisoning: a current review. Arch Lebensmittelhyg 61:197-236.

Johler S, Weder D, Bridy C, Huguenin MC, Robert L, Hummerjohann J, Stephan R, 2015b. Outbreak of staphylococcal food poisoning among children and staff at a Swiss boarding school due to soft cheese made from raw milk. J Dairy Sci 98:2944-8.

Karch H, Tarr PI, Bielaszewska M, 2005. Enterohaemorrhagic Escherichia coli in human medicine. Int J Med Microbiol 295:40518.

Kearney J, 2010. Food consumption trends and drivers. Philos Trans R Soc Lond B Biol Sci 365:2793-807.

Krämer J, Prange A, 2017.
Lebensmittel-Mikrobiologie. $7^{\text {th }}$ ed. Eugen Ulmer KG, Stuttgart, Germany.

Le Loir Y, Baron F, Gautier M, 2003. Staphylococcus aureus and food poisoning. Genet Mol Res 2:63-76.

Lopez-Valladares G, Tham W, Parihar VS, Helmersson S, Andersson B, Ivarsson $\mathrm{S}$, Johansson $\mathrm{C}$, Ringberg H, Tjernberg I, Henriques-Normark B, Danielsson-Tham M-L, 2014. Human isolates of Listeria monocytogenes in Sweden during half a century (1958-2010). Epidemiol Infect 142:2251-60.

MacDonald DM, Fyfe M, Paccagnella A, Trinidad A, Louie K, Patrick D, 2004. Escherichia coli O157:H7 outbreak linked to salami, British Columbia, Canada, 1999. Epidemiol Infect 132:283-9.

Otter JA, French GL, 2010. Molecular epidemiology of community-associated meticillin-resistant Staphylococcus aureus in Europe. Lancet Infect Dis 10:227-39.

Regmi A, 2001. Changing structure of global food consumption and trade. Economic Research Service (ERS), United States Department of Agriculture (USDA). Available at: http://www.ers.usda.gov/publications/pub-details/?pubid=40319. Accessed 10 February 2018.

Schimmer B, Nygard K, Eriksen HM, Lassen J, Lindstedt BA, Brandal LT, Kapperud G, Aavitsland P, 2008. Outbreak of haemolytic uraemic syndrome in Norway caused by $\mathrm{stx}_{2}$-positive Escherichia coli O103:H25 traced to cured mutton sausages. BMC Infect Dis 8:41.

Sonntag AK, Bielaszewska M, Mellmann A, Dierksen N, Schierack P, Wieler LH, Schmidt MA, Karch H, 2005. Shiga toxin 2e-producing Escherichia coli isolates from humans and pigs differ in their virulence profiles and interactions with intestinal epithelial cells. Appl Environ Microbiol 71:885563.

Vanderhaeghen W, Hermans K, Haesebrouck F, Butaye P, 2010. M e t h i c i 11 i n - res is t a n t Staphylococcus aureus (MRSA) in food production animals. Epidemiol Infect 138:606-25.

Zweifel C, Giezendanner N, Corti S, Krause G, Beutin L, Danuser J, Stephan R, 2010. Characteristics of Shiga toxin-producing Escherichia coli isolated from Swiss raw milk cheese within a 3-year monitoring program. J Food Prot 73:88-91.

Zweifel C, Rusch M, Corti S, Stephan $\mathrm{R}, 2006$. Untersuchungen $\mathrm{zu}$ verschiedenen mikrobiologischen Parametern in Rohmilch und Rohmilchkäse einer Biokäsereigenossenschaft. Arch Lebensmittelhyg 57:13-6.

Zweifel C, Schumacher S, Beutin L, Blanco J, Stephan R, 2006. Virulence profiles of Shiga toxin 2e-producing Escherichia coli isolated from healthy pig at slaughter. Vet Microbiol 117:328-32. 